\title{
Política exterior como política pública: reflexiones teóricas y metodológicas en marco del caso de la República Argentina
}

\author{
José Fernández Alonso * \\ Julieta Zelicovich ${ }^{* *}$
}

\section{Resumen}

El presente artículo se propone analizar las referencias a la política exterior como política pública en la producción científica contemporánea de la República Argentina. De modo específico, escruta el modo en el que dicha noción fue definida y operacionalizada por la academia durante las últimas décadas. En el análisis de los alcances y limitaciones de tales definiciones y operacionalizaciones, el trabajo proyecta contribuir a las discusiones teórico-metodológicas en torno a la identificación de la política exterior como política pública, y tras ello, a la construcción de puentes entre los campos de estudio dedicados al Análisis de la Política Exterior (APE) dentro de las Relaciones Internacionales (RRII) y de las políticas públicas en la Ciencia Política.

Palabras claves: Política exterior - Política Pública - República Argentina - Teoría de las Relaciones Internacionales - Metodología de las Relaciones Internacionales

\begin{abstract}
This article aims to analyze the references to foreign policy as public policy in contemporary scientific production in the Argentine Republic. Specifically, it scrutinizes the way in which this notion was defined and operationalized by academia during the last decades. In analyzing the scope and limitations of such definitions and operationalizations, the work plans to contribute to the theoretical-methodological discussions around the identification of foreign policy as public policy, and after that, to the construction of bridges between the fields of study dedicated to the Analysis of Foreign Policy (APE) within International Relations (IR) and Public Policies in Political Science.
\end{abstract}

Keywords: Foreign Policy - Public Policy - Argentine Republic - Theory of International Relations Methodology of International Relations

TRABAJO RECIBIDO: 23/11/2021 TRABAJO ACEPTADO: 23/12/2021

(c) (1) (2)

Esta obra está bajo una licencia internacional https://creativecommons.org/licenses/by-sa/4.0/

\footnotetext{
${ }^{*}$ Doctor en RR.II.; Máster Universitario en Agente Financiero y Negocio Bancario; Investigador Adjunto CONICET; Investigador del Centro de Investigaciones en Política y Economía Internacional (CIPEI); Docente en Facultad de Ciencia Política y RR.II., UNR.

Email: josefernandezalonso@,conicet.gov.ar

** Doctora en RR.II., Mg. en Relaciones Comerciales Internacionales. Investigadora Asistente de CONICET; Investigadora del Centro de Investigaciones en Política y Economía Internacional (CIPEI). Docente en Facultad de Ciencia Política y RR.II., UNR. Email: julieta.zelicovich@,fcpolit.unr.edu.ar
} 


\section{Introducción}

Durante los últimos años, se replicaron de modo creciente los llamados de referentes de las Relaciones Internacionales (RRII) -de los dedicados al Análisis de Política Exterior (APE), en particular- a concebir a la política exterior como una política pública. Lejos de constituirse como un impulso antojadizo y/o pasajero propio de una moda académica, estas proclamas propugnan una reconfiguración de los discursos y praxis disciplinares al apuntalar un conjunto de posicionamientos teórico-metodológicos como así también ontológicos y epistemológicos distanciados, cuando no contrapuestos, de las corrientes tradicionales de las RRII y del APE, en especial.

A tales efectos, se advierte que caracterizar a la política exterior como política pública implica presumir una manera particular de entender la formulación e implementación de las políticas que hacen a la inserción internacional de los Estados, de la República Argentina, por caso, que rompe con el supuesto del Estado como Actor Racional Unificado e ilumina y problematiza las variables domésticas. Además, las convocatorias académicas orientadas a pensar a la política exterior como política pública suponen una invitación al debate tanto intracomo interdisciplinar. En este respecto, se advierte que la caracterización de la política exterior en tanto política pública incita al intercambio constructivo de posiciones entre internacionalistas provenientes de diferentes escuelas o trayectorias de la disciplina, como así también al entramado de discusiones con especialistas de la Ciencia Política, con aquellos abocados al análisis de las políticas públicas, en lo fundamental.

En términos generales, las referencias académicas a la política exterior en tanto política pública suelen estar asociadas al reconocimiento de la relevancia y/o primacía de los condicionantes domésticos en la misma (Busso, 2019). En forma adicional, las alusiones a la política exterior como política pública estilan referir a la participación de actores no tradicionales en los procesos de toma de decisiones -poder legislativo, partidos políticos, organizaciones no gubernamentales, entre otros-, asociando estas referencias de política pública a la fragmentación y/o descentralización decisoria propia de un régimen democrático (Garcé y López, 2014; Milani, 2015; Salomón y Pinheiro, 2013; Van Klaveren, 1992). Lo propio puede señalarse respecto a la ponderación de temas tradicionalmente abordados como de "baja política" dentro de las agendas propias de las políticas exteriores de los Estados (Ingram y Fiederlein, 1997; Milani y Pineiro, 2013). Finalmente, e intrínsecamente vinculado a lo anterior, la identificación de la política exterior como política pública por parte de la Academia suele remitir a los juegos de poder, del reparto de ganadores y perdedores, subyacente en cada discurso y acción constitutivo de la política exterior de un actor estatal en la arena internacional (Lima, 2000). Así pues, puede advertirse que no hay (aún) una convención acabada e indiscutida en términos disciplinares en torno a qué, cómo y cuándo la política exterior debe y/o puede ser entendida como política pública.

Esta multiplicidad de concepciones y/o recursos de la idea de la política exterior como política pública ha sido advertida -y problematizada, consiguientemente- por estudiosos de diferentes latitudes, quienes han ensayado una multiplicidad de explicaciones alternativas para dar cuenta de esto: el carácter cambiante de la política exterior en tanto objeto de estudio (Charillon, 2020; Lima, 2000; Milani, 2015; Risse, 2013), la ausencia de una teoría general del Estado en las RRII (Lentner, 2006), la exigua comunicación entre las trayectorias de investigación y enseñanza de las RRII y de los estudios de políticas públicas (Brummer et. al, 2019; Kaarbo, 2015 y 2019; Lentner, 2006), entre otras.

Todas estas formulaciones tentativas resultan ciertamente válidas para comprender las referencias y/o tratamientos disímiles de la política exterior como política pública en el ámbito 
académico de América Latina y de la República Argentina, en especial. En este marco, reparamos que hasta hace pocas décadas los análisis se distanciaban de la noción de política exterior como política pública, imputándose este uso exiguo a la centralización y unificación de los procesos de toma de decisión propia de los regímenes cívico-militares y del déficit democrático consiguiente (Lasagna, 1996; Lima, 2000; Milani, 2015; Nohlen y Fernández, 1991). Del mismo modo, la ausencia de acuerdo sobre el particular podría atribuirse en parte al escaso sino nulo diálogo entre los campos de estudio propios de las RRII y de las políticas públicas. Si bien ya han transcurrido décadas de la restauración democrática y los procesos decisorios han reportado una significativa descentralización y fragmentación, el encuentro teórico-conceptual entre los especialistas dedicados al APE y a las políticas públicas sigue todavía rezagado. Como consecuencia, se observa una expansión de la discusión y uso del abordaje de la política exterior como política pública, aunque perdura la falta de una noción única que lo defina.

El trabajo aquí desarrollado proyecta contribuir a las discusiones sobre la conceptualización y operacionalización de la política exterior como política pública dentro de la disciplina de las RRII contemporánea, explorando los alcances y límites de las mismas. En términos específicos, el artículo aquí presentado se propone analizar las referencias a la política exterior como política pública en la producción científica contemporánea de la República Argentina. En el desplegar de tal objetivo, el trabajo se apresta a indagar las implicancias de identificar la política exterior como política pública desde marcos cognitivos y/o teóricos del Sur. En forma concurrente, la comunicación prevé contribuir a la reflexión en torno qué significa concebir la política exterior como política pública en el contexto de un orden internacional signado por significativos cambios, tanto en su dinámica como estructura.

En lo que respecta al plano metodológico, señalamos que el trabajo se desarrolla a partir de la selección, sistematización y análisis de contenido de la literatura teórica de política exterior como política pública, como también de la literatura de política exterior argentina reciente. Para su realización, desarrollamos una selección de artículos académicos, capítulos de libros y libros en los que las referencias conceptuales a la "política exterior como política pública" estaban explícitamente mencionadas.

Luego de esta introducción, el artículo se despliega en tres apartados adicionales y unas reflexiones finales a modo de conclusión. En el próximo acápite se presentan las consideraciones generales del abordaje que la Academia ha asignado a la política exterior como política pública. Seguidamente, ahondamos en la discusión sobre la operacionalización de este concepto en los análisis de política exterior argentina (PEA). Finalmente, sugerimos algunos desafíos que esta literatura presenta en razón de los cambios de reciente acontecimiento en el orden internacional.

\section{La política exterior como política pública: a propósito de sus usos disciplinares en el plano global y regional}

Tal como lo nota Lentner (2006), la iniciativa de identificar a la política exterior como una política pública particular dista de ser una novedad dentro de las RRII. En este sentido, y siguiendo con el análisis del mencionado autor, puede advertirse que los primeros trazos disciplinares en esta dirección pueden rastrearse en el promediar de la década del 50, muy especialmente en marco de los trabajos seminales de Snyder et al. (1954 y 1962). Lejanos en objetivos y posibilidades de realizar una revisión exhaustiva de las mencionadas contribuciones, nos limitamos en este marco a señalar que las mismas pusieron en consideración la oportunidad de concebir a la política exterior como la resultante de un proceso de toma de decisiones signado por tensiones y/o confrontaciones de actores gubernamentales con percepciones e intereses contrapuestos. Estas proposiciones, bien vale agregar, implicaban un desafío abierto a la noción de un interés nacional sempiterno e inmutable tal cual lo sostenido por la entonces 
mainstream disciplinar. Llegado a este punto, y en continuidad con lo formulado por Milani y Pinheiro (2013), resulta conveniente subrayar que la propuesta analítica formulada por Snyder y sus coautores no puede considerarse sino en clave de diálogo y/o continuidad con los trabajos de Sprout y Sprout (1956) quienes subrayaron la importancia de las percepciones e interpretaciones sobre el contexto internacional de individuos y grupos en los APE.

Tal trayectoria detractora de los presupuestos realistas en torno a la identificación del Estado como actor racional unificado y de la política exterior en tanto conjunto de acciones y reacciones frente a las limitaciones y oportunidades del escenario internacional fue proseguida años más tarde por Rosenau (1967) al profundizar la premisa de que los actores y procesos domésticos no podían ser desconsiderados de ningún estudio dedicado al APE. Conforme su perspectiva, la política exterior no podía ser concebida como un mero cúmulo de respuestas de un Estado a las variables sistémicas. A tales efectos, debían ponderarse también los derroteros políticos, económicos y sociales del ámbito doméstico. En palabras de Ferreira Sorgine y Castro Santos (2018, pág. 9), para Rosenau, la política exterior no se circunscribiría en un ámbito específico "del dentro o del afuera", sino más bien en las fronteras, "en el interregno de la arena internacional y la doméstica". Si bien el propósito de configurar una teoría general de la política exterior a partir de una sistematización de las vinculaciones o eslabonamientos entre la dimensión doméstica y la internacional no tuvo los resultados esperados por Rosenau ${ }^{1}$, sus trabajos marcaron un nuevo hito en la empresa de la desmitificación de la idea de la autarquía de la política exterior respecto a los procesos y fenómenos acaecidos en el ámbito interno.

En correspondencia con lo formulado por Salomón y Pinheiro (2013), se impone necesario destacar dentro de esta trayectoria a los abordajes sociocognitivos, los cuales respaldados en desarrollos teóricos propios de la Psicología Social y la Psicología Cognitiva propusieron escrutar la importancia de las creencias, las percepciones y las imágenes en el procesamiento de información de los tomadores de decisión tanto en términos individuales Jervis (1976), Jervis, Lebow y Stein (1985), Glad (1989) o George (1991), entre ellos-, o grupales -Janis (1972), por caso-.

La empresa teórico-disciplinar disruptiva propulsada por diversos referentes del APE a instancias de las manifestaciones en pos de "abrir la caja negra" del Estado se profundizó y complejizó de modo cabal con las contribuciones de Allison (1969) y sus modelos de análisis para las decisiones de política exterior. En este punto, consideramos necesario remarcar que tanto el modelo de comportamiento organizacional o burocrático como el de política gubernamental avanzaron sobre la noción de la política exterior como una instancia en la que burocracias y agentes concurren para delinear y/o generar un resultado cercano a sus propios intereses.

Por último, ha de reconocerse en la teoría de los dos niveles de Putnam (1988) como otra de las referencias obligadas en esta trayectoria de la disciplina de las RRII de considerar a la política exterior a la luz de las herramientas teórico-conceptuales de los estudios de políticas públicas. La contextualización analítica de las negociaciones internacionales como elementos constitutivos de la política exterior bajo el condicionamiento de las pujas domésticas mediatizado por los "conjuntos ganadores" factibles de ser ratificados- y la reverberación entre niveles -dando cuenta de una dinámica interactiva- se constituyen en pilares de las construcciones conceptuales posteriores en el enfoque aquí estudiado. En este sentido, se advierte que en virtud de estos aportes, el APE cimentó el camino para concebir a la política exterior -a las negociaciones internacionales, como una de sus manifestaciones más visibles de ella- como un terreno atravesado por disputas de poder. En suma, un quiebre significativo de aquella concepción romántica de la política exterior como un espacio "ascético" y reservado en su diseño e implementación a una élite burocrática celosa de un interés nacional superior e inmutable.

\footnotetext{
${ }^{1}$ Para profundizar sobre los alcances y limitaciones de la obra de Rosenau en el marco de esta trayectoria teórica-metodológica, se sugiere Osorno (1995) y Salomón y Pinheiro (2013).
} 
En conformidad con las formulaciones de Milani y Pinheiro (2013), resulta oportuno notar que la publicación y difusión de Theory of International Politics de Waltz (1979) marcó un repliegue para los estudios orientados al APE. En este sentido, advertimos que la reconsideración de las variables estructurales/sistémicas como elemento explicativo basal del accionar de los actores internacionales, asestó un significativo impacto en el desarrollo de la trayectoria académica-disciplinar promotora de entender a la política exterior en tanto política pública. No obstante, y en plena sintonía con los autores recién referenciados, es de advertir que las significativas transformaciones operadas en la arena internacional durante los últimos decenios reanimaron y dinamizaron el campo de estudio afectado al APE. Al parecer de estos autores:

La simultaneidad de procesos -tales como el fin de la competencia bipolar, la diversificación de coaliciones, los procesos de globalización y liberalización económica, las crisis financieras de orden sistémico, la revolución tecnológica en el área de la información y el accionar transnacional de redes de activismo y de movimientos sociales, entre otros- produjo una inflexión en las concepciones contemporáneas sobre el papel del Estado y sus prácticas en el campo de la política exterior. Surgieron nuevas posibilidades de acción internacional por parte de los Estados, pero también nuevas limitaciones (Milani y Pinheiro, 2013, pág. 15).

Tal como se manifestó en las líneas introductorias, las referencias a la política exterior como política pública han sido crecientes en la literatura académica de las RRII, y de la centrada en el APE, en especial. Este enfoque emerge, como vimos, como parte de la evolución disciplinar y permite dar cuenta de procesos y acciones de política exterior que desde la mirada del interés nacional en clave sistémica no lograban ser explicadas. De allí su relevancia. Empero, este recurso incremental a la noción de política exterior como política pública se desplegó sin encontrar un consenso cerrado respecto a sus alcances y limitaciones. En este sentido, la revisión bibliográfica general nos hizo reportar que en la identificación de la política exterior como política pública, los diferentes autores acentúan diferentes aspectos: ponderación de las variables domésticas como herramientas explicativas de los cursos de acción de los Estados; ampliación de los temas y actores involucrados en el diseño e implementación de la política exterior; descentralización y fragmentación del proceso de toma de decisiones en marco de un proceso de democratización de las vinculaciones Estados/sociedad, entre otros.

En este marco, sostenemos que no resulta ajena a esta mentada falta de consenso, las discusiones inacabadas dentro de la propia trayectoria de indagación de las políticas públicas respecto a la definición fundacional u ordenadora de ésta. En este respecto, y siguiendo las formulaciones de Nelson (1996, pág. 471), puede advertirse que "curiosamente, existen muy pocas definiciones de política pública como campo de estudio dentro de la disciplina (de la Ciencia Política)". De acuerdo con la perspectiva de la mencionada autora, la mayor parte de sus colegas evaden la enrevesada tarea de la definición para rápidamente centrarse en otras. Como excepción, recupera la definición propuesta por Anderson (1990) quien entiende a la política pública como un curso de acción intencional seguido por un actor o conjunto de actores al tratar con un asunto de interés público. Otra definición con gran repercusión es la propuesta por Dye quien de modo tan sucinto como tautológico define a la política pública "como todo aquello que un gobierno hace o deja de hacer" (Dye, 1997, pág. 1). Peters, por su lado, entiende a la política pública como "el conjunto de actividades forjadas por los gobiernos con el propósito de cambiar la economía y la sociedad" (Peters, 2015, pág. 3). Por último, Wilson sostiene que la política pública refiere a las "acciones, objetivos y pronunciamientos que los gobiernos adoptan sobre un asunto en particular, los pasos seguidos (o no seguidos) para su implementación, y las explicaciones dadas por lo sucedido (o no sucedido)" (Wilson, 2006, pág. 154).

Sin ánimo alguno de clausurar el debate de las definiciones constitutivas de este campo de estudio, advertimos que es esta última la que nos resulta más comprehensiva, y por lo tanto, la más pertinente en la caracterización de la política exterior como política pública. Esto es así 
ya que permite contextualizar a la política exterior en el marco de un proceso general, orientado por el gobierno, en el que se reconocen tres instancias: diseño, implementación y comunicación. En cada uno de estos momentos, el gobierno reconoce diversas alternativas para seguir, incluyendo entre ellas la opción de no proseguir acción, objetivo o pronunciamiento alguno, en tanto modalidad específica de concebir y construir política. Dentro de tal abanico de alternativas, se ponderan opciones en torno a los grados de apertura/clausura y de fragmentación/centralización del proceso decisorio y, junto a ello, al modo en el que se gestiona(rá) el enfrentamiento de intereses entre los diferentes actores intervinientes. Llegado este punto, creemos que resultan más que pertinentes los planteos de Garcé y López (2014):

Al igual que toda política pública, la política exterior se iniciará a partir de un diagnóstico -nunca neutro, pues prefigura las soluciones-, de una forma de comprender el escenario y de una definición de los problemas a resolver o desafíos frente a los que actuar. La construcción conceptual de los problemas, la formulación de las posibles soluciones, la inclusión en la agenda, su negociación, la toma de decisiones, la implementación, el monitoreo y la evaluación comparten una dinámica comparable a la de cualquier política pública (pág. 2).

En continuidad con el ejercicio de extender la definición de Wilson al ámbito de la política exterior, es dable remarcar que el proceso involucrado en el diseño, implementación y comunicación de una política pública no versa en torno a cualquier asunto, sino sobre aquellos en los se identifica como necesaria la adopción de un curso determinado. Así pues, el curso tomado no es, por cierto, azaroso o espasmódico sino que se inscribe dentro de una lógica planificación y coordinación (Policy). Por último, la definición anterior da cuenta de las explicaciones que el gobierno y los decisores en particular deben dar en relación con lo acontecido durante el proceso. Esta necesidad de rendir cuentas (accountability) frente a otros actores y a la sociedad en general ubica a dicha política pública -la política exterior, por casodentro de un régimen democrático. En breve, se trata de un conjunto de acciones, objetivos y pronunciamientos que procura contar con la aprobación de los actores interesados y de la sociedad, en general.

En la construcción de puentes de comunicación entre los campos de estudio dedicados al APE y al de las políticas públicas, se impone considerar los cuatro imperativos intelectuales propuestos por Nelson (1996) para abordar a toda política pública, a saber: 1) el holismo, esto es, una vocación por comprehender a dicha política en marco de los procesos y patrones del sistema político en que se inscribe en general; b) el reconocimiento de la importancia de las acciones gubernamentales y de sus consecuencias; c) el carácter instrumental del conocimiento producido en torno a la política en cuestión, ello, tanto en términos teóricos como empíricos; d) la convicción sobre la importancia de la democracia en instancias de la elaboración y la implementación de dicha política.

Tal como marcan Ferreira Sorgine y Santos (2018), el abordaje de la política exterior puede encuadrarse oportunamente con los postulados de Nelson recién referenciados. Pero ello, sin desconocer la peculiaridad de la política exterior frente al resto de las políticas públicas. Llegado a este punto, creemos conveniente reparar que no obstante reconocer la potencialidad sinérgica del encuentro teórico-metodológico de las trayectorias de investigación del APE y de las políticas públicas, no debe desconocerse las características específicas de la política exterior. En este contexto, y en coincidencia con el análisis de Van Klaveren (1992), Lima (2000), y Charillon (2017) entre otros, debe marcarse que el ámbito de proyección de la política exterior está puesto no sólo en el escenario doméstico, sino también, en el externo. Esta especificidad hace que las distancias entre los objetivos y los resultados sean mayores que el resto de las políticas públicas, habida cuenta de que los decisores cuentan con menos herramientas para gestionar la(s) respuesta(s) de los destinatarios externos de las acciones, objetivos y 
pronunciamientos constitutivos de la política exterior. Por cierto, no es ésta la única diferencia identificable entre la política exterior y el resto de las políticas públicas. En conformidad con el trabajo de Kaarbo (2019), advertimos que la política exterior presentaría particularidades no sólo en lo concerniente al contexto en el que se proyecta primariamente, pero también en términos de las prácticas políticas y de los procesos de toma de decisión que la atraviesan.

En lo que respecta al contexto al que se dirige, creemos importante destacar que si bien el contexto internacional deviene el ámbito de proyección por antonomasia de la política exterior, no debe desconocerse que buena parte de las acciones, objetivos y pronunciamientos identificados como constitutivas de la misma están direccionadas al ámbito doméstico. Esto último, se evidencia, por ejemplo, en aquellas referencias que dan cuenta de acciones y/o discursos para "consumo doméstico". Dicho esto, se destaca que la proyección primaria externa de la política exterior incita a que ésta se desarrolle en un ambiente más competitivo y de desconfianza que el resto de las políticas públicas. Del mismo modo, se trataría de un contexto más ambicioso, ambiguo y de normas disputadas, lo cual se traduciría en mayores problemas de acción colectiva.

En relación con las diferenciaciones de las praxis políticas, Kaarbo remarca que la política exterior reportaría mayores dificultades en materia de la problematización y/o estructuración de los problemas y de una falta de claridad de antemano de las preferencias del complejo de actores interesados y alcanzados por ésta.

Por último, en lo que atañe a las peculiaridades de la política exterior en su proceso decisorio, la autora mencionada rescata que, en términos generales, esta política se caracteriza por una mayor centralización, baja institucionalización y secretismo. Con todo, la autora reconoce que estas diferencias no serían más que en grado, por lo que no se inhabilitaría la propuesta teórico-metodológica de abordar la política exterior como política pública. De tal forma, y conforme profundizaremos más adelante, los significativos cambios instrumentados en la arena internacional durante los últimos decenios han ido desdibujando cada una de estas peculiaridades.

En función de lo antedicho, hacemos propias las palabras de Brummer et al. (2019) al asestar que:

La política exterior no necesita ser idéntica a cualquier otra área de la formulación de políticas públicas para que la aplicación de enfoques de política pública tenga sentido. De hecho, si bien la formulación de la política exterior puede contener aún características que no se pueden encontrar en la misma medida en el ámbito de la formulación de otras políticas públicas, las diferencias parecen reportarse en grados y no en lo sustantivo (pág. 9).

En la siguiente sección daremos cuenta de los matices que estas definiciones han adquirido en la Academia argentina.

\section{El abordaje de la política exterior como política pública en el marco de la realidad argentina.}

En la Argentina, a medida que las discusiones conceptuales en torno a la política exterior como política pública fueron ganando peso en la agenda académica, más estudios internalizaron esta visión. Incorporarla significó trascender las consideraciones de la política exterior en términos de temas de agenda y relaciones claves, para enfocar en las relaciones de poder que impulsan esas políticas y los procesos de decisión e implementación de las mismas. En ello, no obstante, hubo un bajo nivel de imbricación entre la literatura de análisis de políticas 
públicas en Argentina -enfocada en la agenda interna- y los estudios específicos de política exterior.

Tal como señalamos arriba, buena parte de los análisis de política exterior argentina (PEA) como política pública implicaron el reconocimiento de la capacidad explicativa de las variables domésticas por sobre, o a la par de, los tradicionales condicionantes externos o sistémicos.

Los trabajos de fines de los años ochenta e inicios de la década del noventa comienzan a introducir nociones de políticas públicas en los análisis de la política exterior argentina, tanto en términos conceptuales como empíricos. El trabajo de Perina (1988) lo hace, por ejemplo, al sugerir el peso de las variables internas, y en particular de los actores que influyen en la política exterior y la internalización de dimensiones como la de cultura política como condicionantes de la política exterior.

Nohlen y Fernandez (1991) se centraron en la transformación acontecida a partir de los procesos de redemocratización. En particular, colocan el foco en la incidencia de los factores político-estructurales y procesos políticos sobre los contenidos de la política exterior argentina. Así, el carácter - y operacionalización- de la política exterior como política pública viene dado tanto por el proceso político que lleva a su formulación como por las características de los temas que aborda. Nohlen y Fernandez (1991) sostienen que:

"los temas de la agenda de política exterior (deuda, comercio, integración) son inseparables de los problemas más agudos y urgentes del campo de las políticas públicas (por ejemplo, el área de la política social). De allí que el tratamiento de uno de estos aspectos involucre inevitablemente el otro" (pág. 236).

Esta conceptualización de la política exterior como política pública propuesta por Nohlen y Fernández es retomada por Tini (2005) quien escruta sobre la incidencia de las particularidades de los procesos de redemocratización para comparar los procesos de formulación e implementación de las políticas exteriores de la República Argentina y Paraguay. Conforme expone oportunamente:

Si postulamos que la política exterior de un estado puede ser entendida como una política pública más del régimen, por tanto, los cambios que se producen en el ámbito de las estructuras y procesos políticos deberían tener una cierta influencia en ella, siendo imposible que un cambio fundamental en las estructuras políticas-institucionales no repercuta en la política exterior (Tini, 2005, pág. 3).

En la obra de Carlos Escudé (1992), una noción relevante es la de la centralidad de los individuos -ciudadanos- en la política exterior. Esto, sin explicitar a la política exterior como política pública, sí alude a lo público de la política exterior ${ }^{2}$. El contenido y destinatario, y las pujas por el mismo, hacen a lo público de la política exterior argentina, en su enfoque.

El abordaje de la Política Exterior Argentina en tanto resultante la interacción de demandas externas y domésticas atraviesan las obras colectivas editadas por el Centro de Estudios en Relaciones Internacionales de Rosario (CERIR) (1994, 1998, 2001, 2006, 2010 y 2014).

\footnotetext{
${ }^{2}$ Años después, sostendría que "Un Estado que genera políticas ciudadano-céntricas será muy diferente de un Estado que genera políticas elite-céntricas o estadista-céntricas. Obviamente, las fuerzas sociales yacen en los orígenes de esta diferencia crucial entre estos tipos de Estados" (Escudé, 2012, pág. 61).
} 
Juan Gabriel Tokatlian y Federico Merke (2014), en el análisis de política exterior como política pública, proponen en cambio una aproximación "estratégico-relacional". En este respecto, sostienen:

La dimensión estratégica alude al hecho de que los actores internos procuran ciertos objetivos y que, para alcanzarlos, deben tomar en consideración las estrategias de otros jugadores. La dimensión relacional implica que el contexto tanto interno como externo- es clave. Por su parte, el contexto remite al papel de los factores tangibles así como de los intangibles (Tokatlian y Merke, 2014, pág. 246).

Los autores mencionados plantean entonces un análisis centrado en el peso de las instituciones y en el comportamiento de los actores. De entre éstos últimos aparece un recorte en favor de los actores estatales. Seis categorías emergen como relevantes al análisis de política exterior como política pública: "(a) el Ejecutivo; (b) gabinetes y burocracias; (c) las provincias; (d) el Legislativo y los partidos políticos; y (e) elites, opinión pública y minorías" (Tokatlian y Merke, 2014: 250)․ En sus conclusiones apuntan a una caracterización de la política exterior argentina como política pública signada por 1) una menor volatilidad que otras políticas públicas, 2) la existencia de un acervo de posiciones tradicionales en términos de contenidos de la PEA, 3) el condicionamiento de compromisos internacionales, 4) un mayor grado de estabilidad ministerial, una burocracia con bases meritocrática, y una cancillería con mayor autonomía relativa, 5) una atención creciente de las unidades subnacionales, y 6) visiones que siendo pluralistas, tienen un alto nivel de continuidad y coincidencia en la opinión pública y elites políticas (Tokatlian y Merke, 2014).

Lo público entendido como resultado de un proceso político colectivo es también la forma de operacionalización de la política exterior como política pública en el trabajo de Busso et al. (2016). En esta obra, los autores subrayan dos características de la política exterior como política pública: por un lado, una de tipo prescriptivo según la cual "debe tomar en cuenta las necesidades e intereses nacionales y buscar soluciones a nivel internacional"; y otra de tipo interactivo o interméstico, a partir de la incidencia simultánea de los condicionantes sistémicos y domésticos. Puntualizan que "no se identifica a los condicionantes domésticos como esencialmente contraproducentes, sino que se evalúa que su exceso -y más aún si estos son consecuencias de crisis recurrentes- afectan el devenir de la acción externa de un país" (Busso, et. al., 2016, pág. 10).

En esa línea argumental, Russell al reflexionar sobre la historia de la PEA indica que "las opiniones diferentes sobre la orientación y contenido de la política exterior son un aspecto natural de la vida política en cualquier país, sobre todo en las democracias. En definitiva, se trata de una política pública sometida a la presión constante de perspectivas e intereses encontrados y, por eso mismo, íntimamente ligada a la política interna” (Russell, 2010, pág 231).

El trabajo colectivo "Los condicionantes internos de la política exterior. Entramados de las relaciones internacionales y transnacionales" coordinado por Míguez y Morgenfeld (2020), es uno de los trabajos más recientes que interpela a la política exterior como política pública. Para ellos, "afirmar que la política exterior es una política pública no constituye ninguna novedad. El tema es definir cómo interpretamos el Estado y sus expresión en forma de políticas" (Míguez y Morgenfeld, 2020, pág 35). La interpretación de este colectivo es ir por el

\footnotetext{
${ }^{3}$ En su obra, el rol de las organizaciones empresariales y sociedad civil no son considerados en este trabajo, en parte por cuestiones de extensión, en parte por menor relevancia, y podemos asumir que también, por una mayor dificultad en acceso a datos.
} 
concepto de Estado "en movimiento" de Oszlak y Odonell (1982), según el cual "la política pública en general -y la política exterior en particular- es resultado de relaciones de fuerza dentro del bloque dominante, pero en el marco de la relación con las clases subalternas" (Míguez y Morgenfeld, 2020, pág. 38). Este planteo lleva a optar por como eje teóricometodológico el abandono de "las visiones estadocéntricas, y atender a la multiplicidad de actores que influyen en la definición de una política exterior", enfatizando "la importancia de los movimientos sociales, de la participación política de distintas organizaciones dentro y por fuera del sistema político" y reconociendo además que "los sectores que instalan determinada cuestión como demanda no solamente se ubican en el plano interno, sino que se incluyen otros actores del plano internacional" (Míguez y Morgenfeld, 2020, pág 38) .

En su conjunto, los análisis de PEA han ido incorporando de manera creciente el reconocimiento de la política exterior como política pública, tanto en los análisis globales de la PEA como en la problematización de cuestiones de agenda específicas, sin haber alcanzado empero definiciones únicas de qué es política exterior como política pública y manteniendo diversos abordajes metodológicos en la operacionalización empírica de este enfoque. Son numerosos los ejemplos de ello. A modo de ilustración y en ninguna manera como lista exhaustiva, mencionamos los trabajos de González Jáuregui (2018) al aplicar el concepto de "trama política" a las relaciones Argentina-China; Zuccarino (2018), respecto de la posición argentina en el conflicto por el Chaco Boreal; Lechini (2014) en relación con las relaciones con Estados de África y Brasil; Eissa (2014), Diamint (2017) y Busso y Barreto (2020), en cuanto a la política de defensa; Bueno $(2012,2018)$, en materia de política ambiental; Sánchez (2015) y Schenoni y Aztiria (2011) respecto del rol del poder legislativo, Malacalza (2014) en materia de cooperación internacional; Zelicovich (2019) y Zelicovich y Zack (2020) en política comercial externa, Bueno y Fernandez Alonso (2021) respecto al rol de los medios y de la opinión pública en la co-construcción de la política exterior, entre otros. Estos trabajos, en sintonía con los elementos identificados en esta sección dan cuenta de las pujas políticas y sociales que subyacen a las decisiones y acciones de la PEA, así como a los mecanismos institucionales y de poder a través de los cuales se implementan. La PEA resulta conceptualizada y evaluada en las intersecciones de la política exterior y otras políticas públicas. Los estudios, con pocas excepciones, mantienen un sesgo hacia la dimensión gubernamental de la cosa pública, con menores incorporaciones de actores no estatales y mecanismos de opinión pública. En su conjunto el enfoque de política exterior como política pública permite, en los casos mencionados, explicar continuidades y rupturas, así como consistencias e inconsistencias, que desde otros enfoques no se avizoran.

\section{Hacia la conceptualización y estudio de la política exterior como política pública desde el Sur y en el marco de incertidumbre global}

Tras el recorrido realizado respecto de los desarrollos del abordaje de la política exterior argentina como política pública, en esta sección nos proponemos identificar algunos de los desafíos analíticos que los cambios en el contexto internacional suponen para la profundización de esa perspectiva.

Como mencionamos, pensar la política exterior como política pública implica dar cuenta del proceso político que subyacen a las decisiones del Estado; la interpenetración de lo doméstico e internacional, y la dispersión de la acción externa en múltiples dimensiones del estado. La política exterior como política pública es, en resumen, ir más allá del Estado como actor racional unificado, y de las relaciones internacionales como vínculos bilaterales y temas de agendas en la presentación de sus contenidos y resultados.

\footnotetext{
${ }^{4}$ Observamos que los capítulos que componen esta obra son ricos en el relevamiento empírico desde estos clivajes, aunque no hay una discusión a posteriori que les de sentido, que los discuta conceptualmente.
} 
Este planteo, además, no es geográficamente neutro, sino situado. Se trata de construir una reflexión de política exterior como política pública desde el sur global. Como sostiene Bueno (2018) "Ser del Sur significa, entonces, tener un pasado y un presente comunes basados en experiencias de pobreza y marginalidad económica y social que aún requieren posiciones de lucha comunes". Esa situación marca un contexto de pensamiento eminentemente distinto al del Norte, que condiciona los marcos en los que se piensan los análisis de política exterior como política pública. En efecto, es menester reconocer (o al menos explicitar) que todo análisis tiene una serie de supuestos en términos de su criterio de demarcación. Calkivik al referir a los análisis de política exterior enfatiza que "las narrativas dominantes dentro de las Relaciones Internacionales están circunscritas en gran medida por sus supuestos sobre quién y qué cuenta y de qué manera, en la práctica y el análisis de la política exterior" (Calkivik, 2020), y agrega que cuestiones como las motivaciones y objetivos éticos, que forman parte de ese "ser global" no suelen ser tenidos en cuenta. Así, cobran peso las variables relativas a sentimientos, identidades y creencias en los análisis de la Política Exterior como política pública. La solidaridad entre pueblos, la empatía en la acción de política exterior, la defensa de valores que no responden a una definición estrecha de interés nacional de bases materiales, son algunos de los ejemplos. ¿De qué manera esos elementos se incorporan en la identificación de un problema de políticas públicas? ¿Cómo obran en la selección de canales de acción? ¿Cuál es la articulación cuando hay actores que tienen imágenes y sentimientos contrapuestos en el proceso político de la política exterior? ¿Qué pasa cuando éstos son distintos a la racionalidad del mainstream? ¿Cómo decidir cuando su ocurrencia es relevante como entidad explicativa de la PEA como política pública?

Asimismo, la noción de Sur (y periferia) lleva a tener en consideración la manera en la que los actores internacionales se imbrican con, o transforman en, actores de la mesa doméstica (especialmente a partir de la inversión extranjera directa y la presencia de corporaciones multinacionales como actores que forman parte de las pujas inherentes a la política exterior como política pública) (Van Klaveren, 1994; Míguez, 2020). Este rasgo es un componente eminentemente del Sur, como países receptores de inversión extranjera directa. Así, como ya ha sido señalado en la literatura numerosas veces -pero no siempre internalizado en los estudios-, la línea que separa la mesa doméstica de la mesa internacional (á la Putnam) es más difusa en el Sur. Entonces ¿Cómo el origen de los capitales configuran las pujas domésticas por las políticas públicas? Ciertamente ello lleva a 1) incluir al sector privado en los análisis y 2) considerar como variable el origen de los capitales -información no siempre disponible-. A modo ilustrativo, la presencia en el proceso político doméstico de corporaciones multinacionales cuyos capitales pertenecen a Europa, Estados Unidos, Japón, etc, ¿Cómo se analizan y operacionalizan en los análisis de Política Exterior Argentina como Política Pública?

A esa noción de Sur y periferia, que obliga a tamizar de manera específica la selección de variables de los análisis de la política exterior como política pública, entendemos que se le agregan, además, las particularidades de ser periferias en un contexto de transición del orden internacional.

Existe bastante consenso en la literatura de las Relaciones Internacionales respecto de que el orden internacional se encuentra atravesando una serie de cambios que distinguen a la era actual del período de guerra fría y del de pos-guerra fría. El punto de quiebre suele ubicarse en la crisis financiera internacional (2008-2009) o en los sucesos que llevaron al referéndum por el Brexit y la elección de Donald Trump (2016). Se destaca como indicadores de estos cambios el menor crecimiento del comercio internacional, el aumento del nacionalismo y del populismo en diferentes lugares del mundo (Hale, Held, y Young 2018) acompañado de una creciente polarización y movilización en torno al desempeño de las instituciones internacionales, no cuestionadas anteriormente (Zürn, 2018). En términos de orden internacional, los rasgos son un menor liderazgo de EEUU a la par de un mayor poder de China. De la misma manera, puede considerarse la existencia de un proceso de difusión del poder -respecto de un momento unipolar- y de segmentación del mismo - con cada vez más distancia entre un conjunto selecto 
de países emergentes y el resto de países-. Se refiere además la expansión de lecturas mercantilistas y lecturas del escenario internacional como un juego de suma cero (Hays, 2017). El orden resultante ha sido caracterizado como "orden geoeconómico" (Roberts, Moraes y Ferguson, 2019), "entrópico" (Schweller, 2014) o bien como "crisis de globalización" (Sanahuja, 2018).

En el ámbito de los análisis de la política exterior esto implica que cuestiones habitualmente ausentes, como la conceptualización de la incertidumbre por parte de los decisores políticos y de las configuraciones sociales que pujan por las políticas, tienen que ser tenidos en cuenta. Es menester reconocer en simultáneo que estos cambios no impactan solo en la política exterior sino en el entramado de otras políticas públicas que dialogan, contraponen y se entrecruzan con ésta en el proceso político subyacente a la acción externa. Siguiendo a Hay, entendemos que estos elementos se constituyen en factores que constriñen con mayor o menor intensidad a las políticas públicas "según lo que los actores hagan de ello" (Hay, 2008, 587), es decir, acorde a su sistema de creencias. Lo que no pueden obturar estas transformaciones es la calidad democrática de la política exterior como política pública, y eso ha de ser integrado en el análisis. Apuntamos entonces que la propuesta de abordar a la política exterior como política pública debe avanzar sobre una serie de interrogantes en ciernes: ¿Cómo los cambios en el sistema internacional impactan en las cualidades del proceso de políticas públicas que hace a la política exterior? ¿Se modifican los actores que intervienen? ¿Los elementos no racionales de qué manera se internalizan y en qué instancias de los procesos decisorios y de implementación? ¿Cómo median estos elementos entre las distintas agencias y actores no estatales de la PEA? ¿Cambian las agendas de la política exterior? Tras ponderar los aportes de la trayectoria del abordaje de la política exterior como política pública a nivel global, regional y nacional, confiamos que la resolución de buena parte de estos interrogantes pasan -y pasarán- por el entrecruce sinérgico de los campos de estudio del APE y de las políticas públicas. En este contexto, entendemos que la continuidad y profundización de ejercicios de triangulación de enfoques teóricos y metodológicos propios de ambas trayectorias de investigación deviene un curso óptimo. En este contexto, asumimos como referencia a la obra colectiva de Brummer et al. (2019), donde se abordan problemáticas variadas de la política exterior a través de teorías de rango medio o específico tales como la teoría de coaliciones, de actores con veto, de equilibrio puntuado, del path dependence, entre otras.

\section{Conclusiones}

Ya no resulta llamativo o inusual encontrar análisis que partan desde la noción de política exterior como política pública. Forjada desde hace décadas a partir de contribuciones detractoras de la idea de un actor racional unificado y de las explicaciones del accionar externo de los Estados fundadas excluyentemente en las variables sistémicas/estructurales, la iniciativa de caracterizar a la política exterior en tanto política pública se acrecentó y profundizó durante los últimos años. A partir de este enfoque se ponderó otro conjunto de explicaciones de la política exterior, que como mencionamos, le dieron sentido a cambios, continuidades, consistencias e inconsistencias que escapaban a las explicaciones alternativas.

En este marco, y tal como se advirtió en el transcurso del artículo, esta propuesta de abordaje contó con crecientes manifestaciones en la literatura académica sobre la política exterior durante las últimas décadas, tanto en los centros de producción científicas emplazados en el Norte como en la Periferia, aunque esto último tiempo más tarde condicionado por el restablecimiento de los regímenes democráticos. Tal como se observó en el transcurso del trabajo, la producción científica sobre la PEA dio cuenta cabal de este fenómeno.

En este proceso supuso una comunicación incremental entre los campos de estudio de la política exterior y de las políticas públicas. Se inscribieron estudios en torno al peso de las variables domésticas en el diseño e implementación de la política exterior, la participación de 
actores desconsiderados por la tradición realista del APE, entre otros. Empero, la referencia incremental de la noción de la política exterior como política pública no se vio acompañada por la construcción de un consenso o convención respecto a la definición y a los alcances de la misma. En este marco, resulta menester reconocer que persiste una distancia entre la declamación de dicho marco teórico y el desarrollo de investigaciones que efectivamente den cuenta de tal carácter. Como se mostró en los apartados anteriores, si bien todos los trabajos partieron del reconocimiento de los condicionantes domésticos como principal variable explicativa, difirieron en el alcance de la internalización de la dimensión de política pública en los abordajes empíricos.

La falta de uniformidad en el tratamiento por parte de los especialistas respecto al uso de la noción de la política exterior como política pública no permite desconocer la existencia de un consenso subyacente -y por tanto, no evidente a primera lectura-, en cuanto a considerar a dicha política como la resultante de una lógica procesal abierta, plural, multinivel, multidimensional, entre otras caracterizaciones.

La brecha entre la enunciación o definición de la política exterior como política pública y su efectiva operacionalización pone en consideración la necesidad de profundizar el estudio teórico y empírico en esta perspectiva, como así también a robustecer las líneas de comunicación con desarrollos provenientes del campo de estudio de las políticas públicas. En este respecto, y en coincidencia plena con Kaarbo (2019), entendemos que la apuesta al mayor diálogo entre estos campos de estudio redundará en profusos beneficios: una ampliación de la agenda de investigación, una mayor y mejor reflexión sobre las conexiones entre lo nacional y lo internacional como asimismo de la naturaleza de la política exterior. En breve, diversas innovaciones teóricas y metodológicas.

Los cambios operados en el escenario internacional y el panorama de incertidumbre consiguiente que ciernen sobre las sociedades contemporáneas -la argentina, por caso- alientan a proseguir avanzando en la construcción de la agenda de investigación fundada y orientada en el diálogo fructuoso entre los campos de estudio del APE y el de las políticas públicas. En consideración de lo antedicho, sostenemos que la continuidad y profundización de la imbricación de estos saberes y tradiciones científico-disciplinares devienen más que promisorias para el abordaje de la PEA, al habilitar un abordaje más comprehensivo y dinámico de los cambios y continuidades así como de consistencias e inconsistencias de esta política pública particular.

\section{Referencias bibliográficas}

Allison, G. (1969). Conceptual Models and the Cuban Missile Crisis. American Political Science Review, 63. 689-718.

Anderson, J. E. (1990). Public Policymaking. Boston, EE.UU.: Houghton Mifflin.

Bouzas, R.; Gosis, P. (2014). Institucionalidad y actores de la política comercial argentina. En Acuña, C. (comp). Dilemas del Estado Argentino: Política exterior económica y de infraestructura en el siglo XXI. Buenos Aires, Argentina: Siglo XXI editores.

Brummer, K.; Harnisch, S.; Oppermann, K. y Panke, D. (2019). Introduction: foreign policy as public policy: exploring promises and pitfalls of public policy approaches for foreign policy analysis. En Brummer, K.; Harnisch, S.; Oppermann, K. y Panke, D. Foreign Policy as Public Policy? Promises and Pitfalls. Manchester, UK.: Manchester University Press. 
Bueno, M. d. P. (2018). Cambio, identidades e intereses: Argentina en las negociaciones multilaterales de cambio climático 2015-2017. Colombia Internacional, n 96: 115-145. https://doi.org/10.7440/colombiaint96.2018.05

Bueno, M. d. P. y Fernandez Alonso, J. (2021). Percepciones sociales en torno a las noticias de Política Exterior Argentina. Una contribución desde el constructivismo. En Bueno, M. y Fernandez Alonso, J. Política Exterior y Medios. Rosario, Argentina: UNR Editora.

Busso, A. (2019). El vínculo entre los condicionantes internos y la política exterior. Reflexiones sobre el caso argentino. Ciclos en la Historia, la Economía y la Sociedad, (52), 3-32. Recuperado a partir de https://ojs.econ.uba.ar/index.php/revistaCICLOS/article/view/ $\underline{1388}$

Busso, A., \& Barreto, L. (2020). Política exterior y de defensa en Argentina. De los gobiernos kirchneristas a Mauricio Macri (2003-2019). URVIO. Revista Latinoamericana De Estudios De Seguridad, (27), 74-93. https://doi.org/10.17141/urvio.27.2020.4376

Busso, A. (Coord) (2016). Modelos de desarrollo e inserción internacional. Aportes para el análisis de la política exterior argentina desde la redemocratización 1983-2011. Rosario, Argentina: UNR Editora.

Centro de Estudios en Relaciones Internacionales de Rosario (CERIR) (1994). La Política Exterior del Gobierno de Menem. Seguimiento y reflexiones al promediar su mandato. Rosario, Argentina: Ediciones CERIR. Ediciones CERIR.

(1998). La Política Exterior Argentina 1994/1997. Rosario, Argentina: (2001). La Politica Exterior Argentina 1998/2001. El cambio de gobierno. ¿Impacto o relevancia?. Rosario, Argentina: Ediciones CERIR.

(2006). La Politica Exterior del Gobierno de Kirchner (Tomo 1 y 2). Rosario, Argentina: Ediciones CERIR - UNR Editora.

(2010). La Politica Exterior de Cristina Fernández. Apreciaciones promediando su mandato. Rosario, Argentina: Ediciones CERIR - UNR Editora.

(2014). La Política Exterior de Cristina Fernández al finalizar su mandato. Rosario, Argentina: Ediciones CERIR - UNR Editora.

Calkivik, A. (2020). Foreign Policy. En Tickner, A. y Smith, K. International Relations from the Global South. London, UK: Routledge.

Charillon, F. (2017). Public Policy and Foreign Policy Analysis. En VVAA. Oxford Research Encyclopedia of Politics. Oxford, U.K.: Oxford University Press.

Dye, T. (1997). Understanding Public Policy (Fifteenth edition). Boston, EE.UU: Pearson.

Eissa, S. (2015). La política de defensa como política pública: el caso argentino (2005-2010). Revista Brasileira de Estudos de Defesa (RBED). Núm.1(1). 162-184

Escudé, Carlos (2012). Principios de Realismo Periférico. Una teoría argentina y su vigencia ante el ascenso de China. Buenos Aires, Argentina: Lumiere.

Escudé, Carlos. (1992). Realismo Periférico. Fundamentos para la nueva política exterior argentina. Buenos Aires, Argentina: Editorial Planeta.

Ferreira Sorgine, G. y Castro Santos, M. E. (2018). A política externa brasileira como política pública: elementos para análise e debate. Meridiano 47, 19: e19009.1-19. DOI: http://dx.doi.org/10.20889/M47e19009

Garcé, A. y López, C. (2014). La política exterior como política pública: Ideas, intereses e instituciones. Debates teóricos recientes desde la Ciencia Política. Paper presentado en la Conferencia FLACSO-ISA 23, Buenos Aires, Argentina. 1-21. Recuperado a partir de 
https://scholar.google.com/citations?view_op=view_citation\&hl=es\&user=E02XFCcA AAAJ\&citation for view=E02XFCcAAAAJ:nb7KW1ujOQ8C

George, A. (1991). La decisión presidencial en política exterior. Buenos Aires, Argentina: Grupo Editor Latinoamericano.

Glad, B. (1989). Personality, Political, and Group Process Variables in Foreign Policy DecisionMaking: Jimmy Carter's Handling of the Iranian Hostage Crisis. International Political Science Review 10. 35-61.

González Jáuregui, J. (2018). El Estado y la trama política del complejo sojero en el vínculo comercial y de inversiones entre Argentina y China, 2002-2015. Ciclos en la Historia, la Economía y la Sociedad, (51), 19-54. Recuperado a partir de https://ojs.econ.uba.ar/index.php/revistaCICLOS/article/view/1354.

Hale, T., Held, D., \& Young, K. (2013). Gridlock: Why Global Cooperation is Failing when We Need it Most. Oxford, UK: Polity Press.

Hay, C. (2009). Globalization and Public Policy. En Goodin, Robert; Moran, Michael; Rein, Martin (ed). The Oxford Handbook of Public Policy. Oxford, UK. DOI: https://doi.org/10.1093/oxfordhb/9780199548453.003.0029

Hays, J. (2017). Embedded Liberalism and the Populist Backlash. Oxford, UK: Oxford University Press

Ingram, H. y Fiederlein, S. L. (1998). Traversing Boundaries: A Public Policy Approach to the Analysis of Foreign Policy. The Western Political Quarterly, New York, v. 41, n. 4.725745.

Janis, I. (1972). Victims of Groupthink. Boston, EE.UU.: Houghton Mifflin.

Jervis, R. (1976). Perception and Misperception in International Politics, Princeton, EE.UU: Princeton University Press.

Jervis, R., Lebow, R. y Stein, J. (eds.). (1985). Psychology and Deterrence. Baltimore, EE.UU: Johns Hopkins University Press.

Kaarbo, J. (2015). A Foreign Policy Analysis Perspective on the Domestic Politics Turn in IR Theory. International Studies Review 17(2). 189-216.

Kaarbo, J. (2019). Conclusion: the promise and pitfalls of studying foreign policy as public policy. En Brummer, K.; Harnisch, S.; Oppermann, K. y Panke, D. (2019). Foreign Policy as Public Policy?: Promises and Pitfalls. Manchester, UK.: Manchester University Press. 218 - 231.

Lasagna, M. (1995). Las determinantes internas de la política exterior: un tema descuidado en la teoría de la política exterior. Estudios Internacionales. $\mathrm{N}^{\mathrm{o}} 111$. 387-408.

Lasagna, M. (1996). Cambio institucional y política exterior: un modelo explicativo Revista cidob d'afers internacionals, 32. 45-64. Recuperado a partir de https://www. cidob.org/es/articulos/revista_cidob_d_afers_internacionals/cambio_institucional_y_pol itica_exterior_un modelo_explicativo

Lechini, G. (2006). Argentina y África en el espejo de Brasil ¿Política por impulsos o construcción de una política exterior?. Buenos Aires, Argentina: CLACSO.

Lentner, H. (2006). Public Policy and Foreign Policy: Divergences, Intersections, Exchange. Review of Policy Research 23(1). 169-181.

Lima, M. R. S. (2000). Instituições democráticas e política exterior. Contexto Internacional, v. 22, n. 2. 265-303. 
Malacalza, B. (2014). La política de cooperación al desarrollo como dimensión de la política exterior desde la Teoría de las Relaciones Internacionales. Mural Internacional, 5(2), 163-176. DOI: $10.12957 / \mathrm{rmi} .2014 .10771$

Míguez, M. (2020). Los factores internos de la política exterior. Hacia la profundización de un debate en las Relaciones Internacionales latinoamericanas. En Miguez, M. C. y Morgenfeld, L. (Coord). Los Condicionantes internos de la política exterior. Entramados de las relaciones internacionales y transnacionales. Buenos Aires, Argentina: Teseo Press.

Milani, C. y Pinheiro, L. (2013). Política Externa Brasileira: Os desafíos de sua Caracterização como Política Pública. Contexto Internacional, Vol. 35, n.1, p.11-41

Milani, C. (2015). Política Externa é Política Pública? Insight Inteligência, v. XVIII. 56-75.

Nelson, B. J. (1996). Public policy and Administration: an Overview. En R. E. Godin y H-D Klingemann (Eds). A new handbook of political science.(pp 559-594). New York, EE.UU: Oxford University Press.

Nohlen, D., y Fernández B., M. (1991). Democratización y política exterior: análisis comparado en torno a tres casos: Argentina, Brasil y Uruguay. Estudios Internacionales, 24(94). 229-259. DOI: $10.5354 / 0719-3769.2011 .15459$

Osorno, G. (1995). El vínculo entre los ámbitos interno e internacional. De la política de eslabones a la diplomacia de doble filo. Foro Internacional. Vol. 35, No. 3 (141), pp. 426-447

Perina, R. (1988). El estudio de la política exterior y las relaciones internacionales argentinas. En Russell, R. y Perina, R. (eds.). Argentina en el mundo (1973-1983). (pp. 11-18) Buenos Aires, Argentina: Grupo Editor Latinoamericano

Peters, B. G. (2015). Advanced Introduction to Public Policy. Cheltenham: Edward Elgar.

Putnam, R. (1996), Diplomacia y política nacional: La lógica de los juegos de doble nivel, Zona Abierta, $\mathrm{N}^{\mathrm{o}} 74$, pp. 69-120.

Ratton Sanchez, M., da Silva, E.C., Cardoso, E. L., y Spécie, P. (2006). Política externa como política pública: uma análise pela regulamentação constitucional brasileira (1967-1988). Revista de Sociologia e Política. (27). 125-143.

Risse, T. (2013). Transnational Actors and World Politics. En Carlsnaes, W.; Risse, T. y Simmons, B. (eds.). Handbook of International Relations, 2nd edition, London: Sage, pp. $453-477$.

Roberts, A., Moraes, C., \& Ferguson, V. (2019). Towards a Geoeconomic Order in International Trade and Investment. Journal of International Economic Law (22), 655-676. doi: $\underline{10.1093 / \text { jiel/jgz036 }}$

Rosenau, J. (Org.) (1967). Domestic Sources of Foreign Policy. Londres, U.K: CollierMacmillan Limited.

Russell, R. (2010). La Argentina del Segundo Centenario: Ficciones y realidades de la política exterior. En Russell, Roberto (ed.). Argentina 1910-2010. Balance del siglo, (pp. 238281) Buenos Aires, Argentina: Aguilar.

Salomon, M. y Pinheiro, L. (2013). Análise de Política Externa e Política Externa Brasileira: trajetória, desafios e possibilidades de um campo de estudos. Revista Brasileira de Politica Internacional, v. 56, n. 1. 40-59.

Sanahuja, J. A. (2018). Crisis de globalización, crisis de hegemonía: un escenario de cambio estructural para América Latina y el Caribe. En Serbin, A. (Coord.) América Latina y el Caribe frente a un Nuevo Orden Mundial: Poder, globalización y respuestas regionales. (pp 37-68) Buenos Aires, Argentina: CRIES - Icaria Editorial. 
Sanchez, L. (2013). Condicionantes internos de la política exterior argentina. La participación del cuerpo decisional legislativo en el diseño de la agenda internacional de la política exterior argentina (1999-2003). Tesis doctoral. Doctorado en Ciencias Sociales. Universidad Nacional de La Plata (UNLP), Argentina.

Sanchez, L. (2015). El papel del Congreso Nacional de Argentina en la elaboración de la política exterior (1999-2003). Un modelo para su análisis. Colombia Internacional, (83), 103-132. https://doi.org/10.7440/colombiaint83.2015.05

Schenoni, L. L., y Aztiria, A. M. (2011). El Congreso en la formulación de política exterior: Argentina y Brasil en perspectiva comparada. Revista Densidades, 7. 79-101.

Schweller, R. (2014). Maxwell's Demon and the Golden Apple. Global Discord in the New Millennium. Baltimore, EE.UU.: Johns Hopkins University Press.

Snyder, R., Bruck, H. W., y Burton, S. (1954). Decision making as an approach to the study of international politics. Foreign Policy Analysis Series No. 3. Princeton, EE.UU.: Princeton University Press.

Snyder, R.; Bruck, H. y Sapin, B. (Org.) (1962). Foreign Policy Decision Making - An Approach to the Study of International Politics. New York, EE.UU.: Free Press.

Sprout, M. y Sprout, H. (1956). Man-Milieu Relationship Hypotheses in the Context of International Politics. Princeton, EE.UU: Princeton University Press.

Tini, N. (2005). Las Variables Domésticas en la Política Exterior: Casos de Argentina y Paraguay. Segundo Encuentro del Centro de Reflexión en Política Internacional: Prospectivas y perspectivas de nuestra política exterior, Instituto de Relaciones Internacionales, Universidad Nacional de La Plata (UNLP), La Plata. 1 de septiembre. Recuperado a partir de http://sedici.unlp.edu.ar/bitstream/handle/10915/36894/ Documento completo.pdf? sequence $=1$

Tokatlián, J. y Merke, F. (2004). Instituciones y actores de la política exterior como política pública. En Acuña, C. (comp.), Dilemas del Estado Argentino, (pp 245-312) Buenos Aires, Argentina: Grupo Editorial Siglo Veintiuno.

Van Klaveren, A. (1992). Entendiendo las políticas exteriores latinoamericanas: modelo para armar., Estudios Internacionales., $25(98), 169-216$, DOI: $\underline{10.5354 / 0719-}$ $\underline{3769.2011 .15463}$

Waltz, K. (1979). Theory of International Politics. Massachusetts, EE.UU: Addison-Wesley.

Wilson R. (2006). "Policy Analysis as Policy Advice". En Moran M., Rein, M. y Goodin, R. (Eds.), The Oxford Handbook of Public Policy. (pp 152-168) New York, EE.UU.: Oxford University Press.

Zelicovich, J. (2019). El sistema de creencias como condicionante de la política exterior argentina en las negociaciones comerciales internacionales, 2008-2018. Ciclos en la Historia, la Economía la Sociedad, (52), 85-107. Recuperado a partir de https://ojs.econ.uba.ar/index.php/revistaCICLOS/article/view/1393

Zelicovich, J., \& Zack, G. (2020). Evaluación Institucional de la Política Comercial Externa. El caso de Argentina. Buenos Aires: Instituto para la Integración de América Latina y el Caribe. Recuperado a partir de_https://publications.iadb.org/publications/spanish/ document/Evaluacion-institucional-de-la-politica-comercial-externa-El-caso-deArgentina.pdf

Zuccarino, M. (2018). La política exterior como política pública. Incidencia de las variables internas en la formulación de la política exterior a partir de un estudio de caso: la posición de la Argentina ante el conflicto por el Chaco Boreal entre Paraguay y Bolivia. Studia Politicae (44). 43-74

Zürn, M. (2014). The Politicization of World Politics and its Effects: Eight Propositions. European Political Science Review 6(1). 47-71. 
Cuadernos de Política Exterior Argentina (Nueva Época), 134, diciembre 2021, pp. 7-24

ISSN 0326-7806 (edición impresa) - ISSN 1852-7213 (edición en línea)

Zürn, M. (2018). A theory of Global Governance: Authority, Legitimacy, and Contestation. Oxford, UK: Oxford University Press. 